\title{
Pensando a consciência coletiva de homens gays: um ensaio para decolonizar o corpo negro
}

\author{
Marcelo Chave Soares ${ }^{1}$ \\ Faculdade Vale do Cricaré
}

Resumo: O presente artigo busca discutir as percepções de homens negros sobre os arquétipos da consciência coletiva de homens gays a respeito do corpo do negro. Assim, aborda-se como estudos decoloniais ajudam compreender a condição de subalternidade de homens negros em relação a membros da comunidade LGBTQIA+, com o contributo teórico formado pelo diálogo entre o conceito de consciência coletiva de Durkheim, os estudos decoloniais e o queer decolonial. E, dessa forma, evidencia-se como a consciência coletiva de homens gays é colonizada pelo ideal da hipersexualização do corpo do homem negro.

Palavras-chave: consciência coletiva; estudos decoloniais; LGBTQIA+.

\footnotetext{
${ }^{1}$ Mestrando em Ciência, Tecnologia e Educação pela Faculdade Vale do Cricaré, Especialista em Sociologia pela Faculdade Futura, possui graduação em Direito pela Faculdade Castelo Branco - FCB, é licenciado em Ciências Sociais pela Universidade Metropolitana de Santos - UNIMES, é licenciado em História pela Universidade de Uberaba - UNIUBE. Atualmente é Advogado, Professor de Sociologia na Educação Básica da Rede Estadual do Estado do Espírito Santo. É membro do Grupo de Pesquisa Educação, História e Diversidades - GPEHDi. Tem seus estudos voltados para a educação, gêneros, sexualidades, direito, cultura e suas representações.
} 


\title{
Thinking gay men collective consciousness: a test to decolonize the black body
}

\begin{abstract}
This article seeks to discuss the perceptions of black men about the archetypes of the collective consciousness of gay men about the body of the black. Thus, it addresses how decolonial studies help to understand the condition of subordination of black men in relation to members of the LGBTQIA+ community, with the theoretical contribution formed by the dialogue between Durkheim's concept of collective consciousness, decolonial studies and decolonial queer. And, in this way, it is evident how the collective conscience of gay men is colonized by the ideal of hypersexualization of the black man's body.
\end{abstract}

Keywords: collective awareness; decolonial studies; LGBTQIA+.

\section{Pensando la consciencia colectiva de los hombres gay: una prueba para descolonizar el cuerpo negro}

\begin{abstract}
Resumen: Este artículo busca discutir las percepciones de los hombres negros sobre los arquetipos de la conciencia colectiva de los hombres gay sobre el cuerpo del negro. Así, aborda cómo los estudios decoloniales ayudan a comprender la condición de subordinación de los hombres negros en relación con los miembros de la comunidad LGBTQIA+, con el aporte teórico que forma el diálogo entre el concepto de conciencia colectiva de Durkheim, los estudios decoloniales y el queer decolonial. Y, de esta manera, se hace evidente cómo la conciencia colectiva de los hombres gay es colonizada por el ideal de hipersexualización del cuerpo del hombre negro.
\end{abstract}

Palabras clave: conciencia colectiva; estudios decoloniales; LGBTQIA+. 
$\mathrm{N}$ ão obstante à importância de Alcione à música popular brasileira, a letra da música Meu Ébano denuncia como o corpo negro é lido na chave da hipersexualização. Compreende-se, portanto, que a condição de subalternidade da população negra se estende às mais diversas searas sociais e, nessa direção, constroem o imaginário social do lugar dos negros: subalternidade e objetificação.

A estrutura imagética do homem negro que povoa o imaginário de alguns homens gays parte do princípio que ele sempre será: viril, másculo, sexualmente inesgotável, forte e "bem dotado" (no que diz respeito ao tamanho do seu pênis). Essas características dispensam quaisquer outras como: afetividade, cultura, educação, dentre outras. Em suma, o homem negro é percebido como um objeto sexual ou um escravo sexual para cumprir o papel de satisfazer os desejos daqueles que o procuram.

Diante dessas questões, surgiram inquietações contidas no presente trabalho. Consideramos este um ensaio introdutório, onde se busca analisar a consciência coletiva de homens gays + a partir da perspectiva de pensamento construída do corpo do homem negro dentro dessa. Tendo em vista que diante do processo de colonização, o corpo negro também foi colonizado a partir do olhar de dominação e exploração. Tal análise é feita a partir das experiências de homens negros, sobre o imaginário de homens gays.

Durante o período em que a escravidão era regulamentada e defendida pelo Estado brasileiro, mulheres e homens negros eram tratados como objetos de seus donos e negados em suas subjetividades. Considerando tal contexto, esses sujeitos eram rogados a condições subumanas, sendo seu propósito único servir a seus donos. Por esse motivo, era comum durante o período colonial, que esses corpos fossem alvos de constantes abusos sexuais.

Demonstra-se, ainda nessa pesquisa, como os estudos decoloniais podem contribuir para desvelar os processos de dominação que foram impostos aos corpos de pessoas negras. E, aqui, abordaremos essa influência dentro da comunidade LGBTQIA+, com ênfase aos homens gays, que reproduz estruturas discursivas que compreendem uma situação de subalternidade aos homens negros.

Entendendo os estudos decoloniais como profícuos ao empoderamento ${ }^{2} \mathrm{de}$ vozes de indivíduos silenciados por mecanismos de poder. O trabalho que se segue adota uma perspectiva que dialogará com esse campo de estudos, através do pensamento de Aníbal Quijano (2005) e Franz Fanon (1968; 2008) ao pensamento durkheimiano sobre consciência coletiva (DURKHEIM, 1995) e ao queer decolonial (PEREIRA, 2015).

As discussões aqui propostas não pretendem encerrar o pensamento, tampouco "colonizar" autores da decolonialidade ao tentar dialogar com outro autor de origem europeia e não decolonial. Mas, por tratar-se de um estudo que analisa

\footnotetext{
2 Embora o poder, de acordo com Foucault (2014) não é algo que possa ser possuído, dado, tirado, transmitido a alguém utilizamos a categoria 'emporamento' como é um jargão utilizado por movimentos sociais. O termo possui diferentes traduções e conceitos, no entanto, para tal pesquisa, entendemos, consoante a Gohn (2004: 23), o empoderamento como “ações destinadas a promover simplesmente a pura integração dos excluídos, carentes e demandatários de bens elementares à sobrevivência, serviços públicos, atenção pessoal etc., em sistemas precários, que não contribuem para organizálos - porque os atendem individualmente, numa ciranda interminável de projetos de ações sociais assistenciais”.
} 
querelas da sociedade, é fundamental que chame ao debate autores da Sociologia Clássica.

Dessa forma, a pesquisa é mista. Apresenta características qualitativas uma vez que nesse tipo de pesquisa "[..] importante a interpretação por parte do pesquisador com suas opiniões sobre o fenômeno em estudo. Neles a coleta de dados muitas vezes ocorre por meio de entrevistas com questões abertas" (PEREIRA et al., 2018: 67). Por outro lado, é quantitativa por trazer, para compor o escopo desse estudo empreendimento, respostas de 19 (dezenove) questionários aplicados juntos a homens negros entre os dias 05/10/2020 e 07/10/2020. Em função do momento de pandemia de Covid-19, estes questionários foram respondidos de forma virtual através de grupos em redes sociais (WhatsApp, Facebook, Instagram); essa medida foi tomada a fim de preservar a saúde dos entrevistados e do pesquisador. No entanto, cabe aqui destacar, que tal metodologia não comprometeu o desenvolvimento do trabalho como demonstrar-se-á.

Com o intuito de estabelecer a discussão de forma coerente, trouxemos a organização deste artigo em três tópicos que se comunicam da seguinte forma: a) percurso teórico do trabalho; b) remonte histórico-social dos estudos decoloniais para a compreensão da situação de subalternidade dos corpos negros e, por fim, c) análise dos dados coletados nos questionários.

\section{Diálogos entre consciência coletiva, decolonialidade e o queer decolonial}

As discussões em torno do conceito de consciência coletiva dentro das Ciências Humanas e Sociais não é uma pauta consensual, dada as diferentes abordagens que são propostas na área. Émile Durkheim (1995), descreve que a divisão social do trabalho contribui para a coesão social dentro da solidariedade orgânica, que consiste nos laços que mantêm unidas as sociedades industriais. Dessa forma, a consciência individual, segundo o autor, ganha maior ênfase nesse modelo de solidariedade.

Enquanto a consciência individual diz respeito às características singulares de cada indivíduo, o sociólogo francês Émile Durkheim (1995) entende a consciência coletiva como conjunto de sentimentos e crenças comuns aos membros de uma mesma sociedade. Dessa maneira, a consciência coletiva pode ser entendida como uma série de valores, tradições, conhecimentos que perfilam o pensamento e o imaginário social e fazem um grupo social pensar de forma minimamente semelhante.

Nestes termos, a consciência coletiva é permeada por diversos condicionantes e, no caso da América Latina, a processo de colonização, expresso também pelo ideal de modernidade também influencia na formação dessa consciência, como demonstraremos nos parágrafos seguintes.

O sociólogo peruano Aníbal Quijano (2005) caracteriza-se como um dos principais pensadores da decolonialidade. $\mathrm{O}$ autor entende que o processo de colonização do continente americano figurou um novo modelo de poder global, embalado pelo progresso do capitalismo, onde o colonial se caracteriza pelo moderno, dando início ao chamado movimento colonialidade/modernidade. Esse novo modelo de poder mundial classificou socialmente a população mundial em conformidade à ideia de raça, que simbolizaria o principal marcador social da diferença entre conquistadores e conquistados. A partir de tal narrativa justificou-se e legitimou-se a dominação colonial (QUIJANO, 2005: 117): 
A ideia de raça, em seu sentido moderno, não tem história conhecida antes da América. Talvez se tenha originado como referência às diferenças fenotípicas entre conquis-tadores e conquistados, mas o que importa é que desde muito cedo foi construída como referência as supostas estruturas biológicas diferenciais entre esses grupos.

Sobre o de dominação, Quijano (2005) entende que houve uma promoção de uma Totalidade europeia, que consistia em comportamentos e valores culturais. Estes, por sua vez, excluíam qualquer outra possibilidade de totalidade diferente ao do conquistador. Essa Totalidade foi propagada como valores universais resultados de esforços e empreendimentos de contextos socioculturais e econômicos da Europa e, portanto, legítimos.

Dessa forma, para colonizar o continente americano, foi necessário também colonizar o seu pensamento, seus costumes e totalidades, redesenhando uma nova consciência coletiva que legitimava a dominação europeia. Na mesma perspectiva colocou-se em lugares subalternos os povos nativos e os afrodescendentes que constituiriam a mão-de-obra para construção de impérios. O marcador de raça aparece, desse modo, como um importante definidor das relações de trabalho e exploração. Tendo em vista que

\begin{abstract}
cada forma de controle do trabalho esteve articulada com uma raça particular. Consequentemente, o controle de uma forma específica de trabalho podia ser ao mesmo tempo um controle de um grupo específico de gente dominada. Uma nova tecnologia de dominação/exploração, neste caso raça/trabalho, articulou-se de maneira que aparecesse como naturalmente associada, o que, até o momento, tem sido excepcionalmente bem-sucedido. (QUIJANO, 2005: 109)
\end{abstract}

Diante disso, observa-se que a divisão social do trabalho, tão importante à formação da consciência coletiva, aparece racializada. Dessa maneira a consciência coletiva também é racializada e marcada pela colonialidade do poder, onde corpos são subalternizados e relegados à escravidão e à servidão daqueles que se julgam seus senhores e donos. Para pensar e repensar essa consciência coletiva, traz-se à tona o pensamento do queer decolonial (PEREIRA, 2015), que busca romper e transgredir as identidades colocadas como prontas e engessadas em fundamentações heterossexistas e reprodutoras de dominação e exploração.

A teoria queer, em vista disso, "busca tornar visíveis as injustiças e violências implicadas na disseminação e na demanda do cumprimento das normas e das conversões culturais, violências e injustiças" (MISKOLCI, 2020: 26). Tendo por base afirmativas como essas, Pereira (2015) aponta que o encontro do queer com o decolonial é fundamental pois assim "como a teoria queer, a crítica decolonial interroga as pretensões teóricas que generalizam pressupostos e assuntos particulares e eludem as formulações dos Outros, consideradas como específicas e particulares" (PEREIRA, 2015: 415).

Apesar das diversas críticas que sofrem, as teorias queer e decolonial possuem semelhanças importantes para romper com determinadas estruturas que contribuem para solidificar a consciência coletiva. Ou seja:

[...] a teoria queer também suspeita de usos identitários reificados, de propostas não atentas às questões de corpo e sexualidade e de um enquadramento geopolítico que olvide que a teoria queer se originou como pensamento inconformado de corpos inconformes que, desde os primeiros momentos, assumiu para si, de forma orgulhosa, um insulto atribuído às partes consideradas abjetas, desprestigiadas. (PEREIRA, 2015: 416)

O rompimento das estruturas que dão base à consciência coletiva que reproduz a dominação e exploração do corpo negro pode ser feito com e por meio de posturas metodológicas e de ação preconizadas no queer e na decolonialidade. Em síntese, sabendo que de acordo com Durkheim (1995) a consciência coletiva 
faz a sociedade se manter coesa, essa coesão tem se dado através de estruturas racistas e sexistas, cabendo, diante disso, ao queer e à decolonialidade desconstruí-la sob o ponto de vista teórico que refletirá no plano prático.

\title{
O negão imagético
}

A condição do corpo de pessoas negras foi colocada em evidência sempre para justificar processos de dominação. A divisão racial que ocorreu na América Latina foi fundamental para distinguir dominantes e dominados. Esse marcador social da diferença mostrou-se protagonista para a posse dos corpos, uma vez que, de acordo com Fanon:

\begin{abstract}
A despeito do sucesso da domesticação, malgrado a usurpação, o colono continua sendo um estrangeiro. Não são as fábricas nem as propriedades nem a conta no banco que caracterizam em primeiro lugar a "classe dirigente". A espécie dirigente é antes de tudo a que vem de fora, a que: não se parece com os autóctones, "os outros". (FANON, 1968: 30 - grifos do autor)
\end{abstract}

Embora Fanon (1968) dê ênfase aos marcadores de raça e à questão da divisão social do trabalho - que também é imprescindível para a colonização da consciência coletiva - destacaremos aqui, a hipersexualização do corpo negro, onde são colocadas em questão características fenotípicas de cunho sexual. Em sua obra "Pele negra, máscaras brancas", o autor discorre sobre a objetificação do negro na condição de subordinado.

\begin{abstract}
Começo a sofrer por não ser branco, na medida em que o homem branco me impõe uma discriminação, faz de mim um colonizado, me extirpa qualquer valor, qualquer originalidade, pretende que seja um parasita no mundo, que é preciso que eu acompanhe o mais rapidamente possível o mundo branco, "que sou uma besta fera, que meu povo e eu somos um esterco ambulante, repugnantemente fornecedor de cana macia e de algodão sedoso, que não tenho nada a fazer no mundo". (FANON, 2008: 94 - grifos do autor)
\end{abstract}

O racismo atua de modo que vai retirar o negro de sua posição de humanidade. Nessa direção, ele se tornará um objeto que atenderá aos desejos daquele que o objetifica, colocando-o em posição de não-humano, como se este não representasse qualquer subjetividade, tratando-o como mero objeto sexual. A respeito disso, Souza esclarece que

o homem negro não é um homem. Como nos lembra Fanon (1983), no imaginário ocidental, um homem negro não é um homem, antes ele é um negro e como tal não tem sexualidade, tem sexo, um sexo que desde muito cedo foi descrito no Brasil com atributo que o emasculava ao mesmo tempo em que o assemelhava a um animal em contraste com o homem branco. (SOUZA, 2009: 100)

As narrativas que envolvem o corpo negro, seja das mulheres, seja dos homens negros, estão repletas de hipersexualização.

A representação, por exemplo, da mulher com seios fartos, pele bronzeada, cintura fina e bunda avantajada e a representação do homem com pele morena, corpo definido e viril são vendidos e retransmitidos ao mundo em uma generalização de uma identidade estereotipada e limitada. E isso acontece em larga escala através da reafirmação feita pelos meios de comunicação de massa. (RODRIGUES, 2020: 274)

O envolvimento sexual entre senhores e escravos, embora fosse considerado comportamento desviante era prática comum no período colonial brasileiro (ALMEIDA, 2013). As sanções para aqueles que se atrevessem a transgredir as hierarquias sociais eram enormes e podiam chegar à pena de morte. A ideia de que homens negros possuem o pênis grande rememora períodos como esses. Uzel 
aponta que o imaginário social construído sobre o homem negro retira dele sua subjetividade.

\begin{abstract}
É o negro visto como o bom de cama, mas alvo dos estereótipos que afetam sua autoestima, pois busca enfatizar diferenças que tentam inferiorizá-lo em relação à construção social do homem branco. É o sujeito que tem a potência do falo, mas está subestimado por não corresponder a padrões eurocêntricos de beleza, subjugado ao lugar das minorias em cargos políticos, em atividades profissionais bem remuneradas, nas universidades e ainda tratado como alvo permanente da opressão policial. (UZEL, 2020: 93)
\end{abstract}

Quando colonizadores desembarcam na África, assustam-se com as imagens criadas a partir do barro do orixá Exu ${ }^{3}$ que era representado como um homem de pênis avantajado, maior que o próprio corpo. Com isso, a Igreja Católica associou Exu à figura ao diabo cristão, por se tratar de um deus de uma cultura diferente da católica e apresentar proeminentes características sexuais (COSTA, 2012), que eram absolutamente silenciadas e proibidas pela Igreja.

O imaginário social do "negão" forte e viril forma-se tendo por base matrizes históricas como essas e, consequentemente, estruturam o pensamento colonial brasileiro. Força e virilidade povoam a construção imagética do homem negro e refletirão também sobre o ideal de pênis.

É importante ressaltar, que na maioria das vezes essa virilidade é associada ao tamanho do órgão sexual masculino. Espera se que as proporções penianas do homem negro sejam "compatíveis" com a sua masculinidade, então virilidade, potência sexual e tamanho do pênis devem ser proporcionalmente equiparadas. (RODRIGUES, 2020: 273)

Sabendo disso, esse arquétipo que ocupa o imaginário social e, do mesmo modo, o imaginário social de parte da comunidade LGBTQIA+, de modo mais específico, homens gays, mostra-se com raízes fincadas na história de colonização brasileira. O período escravagista que transformou a escravidão numa instituição social, reverbera na contemporaneidade sem intenção de disfarce. A condição de "negão" que se espera de homens negros é resultado desse processo exploratório e silenciador da população negra. Um corpo forte, viril, sexualmente atraente, inesgotável e disponível para saciar os desejos daqueles que o fetichizam.

\title{
Consciência coletiva de homens gays e o corpo do homem negro
}

A fim de compreender como homens negros, a partir de suas experiências, entendem o imaginário da consciência coletiva de homens gays sobre sua representação imaginária, nesta seção, discutiremos alguns dados dos questionários respondidos. Para tanto, faremos uma reconstrução do perfil dos sujeitos da pesquisa. Ressaltamos que a identificação dos entrevistados não era obrigatória, portanto, os dados não apresentam nomes ou quaisquer outras formas de identificar os sujeitos participantes da pesquisa.

Dos sujeitos que participaram da pesquisa, 63,2 \% se identificam como negros e 36,8\% se identificam como pardos (Figura 1), 100\% se identificam como homens cis (Figura 2); cerca de 63,2\% se identificam como gays, 21,1\% como bissexuais e 15,8\% como heterossexuais (Figura 3). A faixa etária dos sujeitos da pesquisa é mista, com idades variáveis entre 18 até 45 anos, e também maiores de 45 anos (Figura 4). Os sujeitos participantes desta pesquisa são provenientes 
de diferentes regiões do país, com a maioria sendo residente na região Sudeste $(47,4 \%)$, seguido da região Nordeste (31,6\%), logo após a região Sul $(15,8 \%)$ e, por fim, a região Centro-oeste (5,3\%), não houve participantes da região Norte por não participarem dos grupos onde foram aplicados os questionários (Figura 5).

Cor / Raça

19 respostas

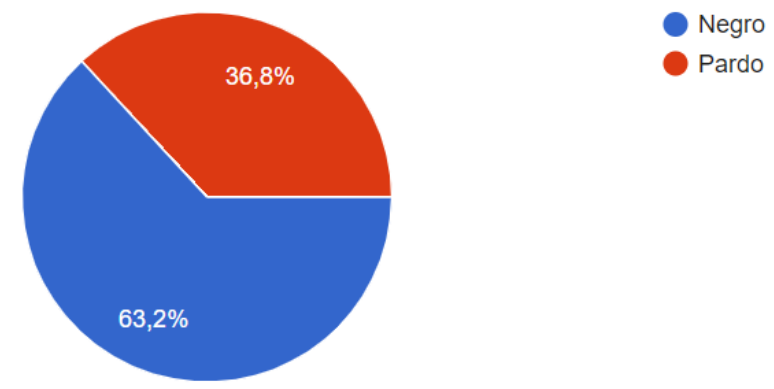

Figura 1. Fonte: Acervo pessoal.

Identidade de Gênero

19 respostas

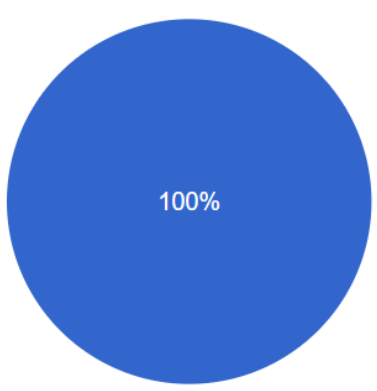

Homens cis

Homens trans

Nenhuma das alternativas

Figura 2. Fonte: Acervo pessoal.

Identidade Sexual

19 respostas

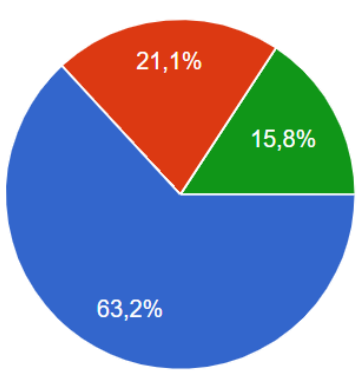

Gay

Bissexual

Assexual

- Heterossexual

- Outros

Figura 3. Fonte: Acervo pessoal. 

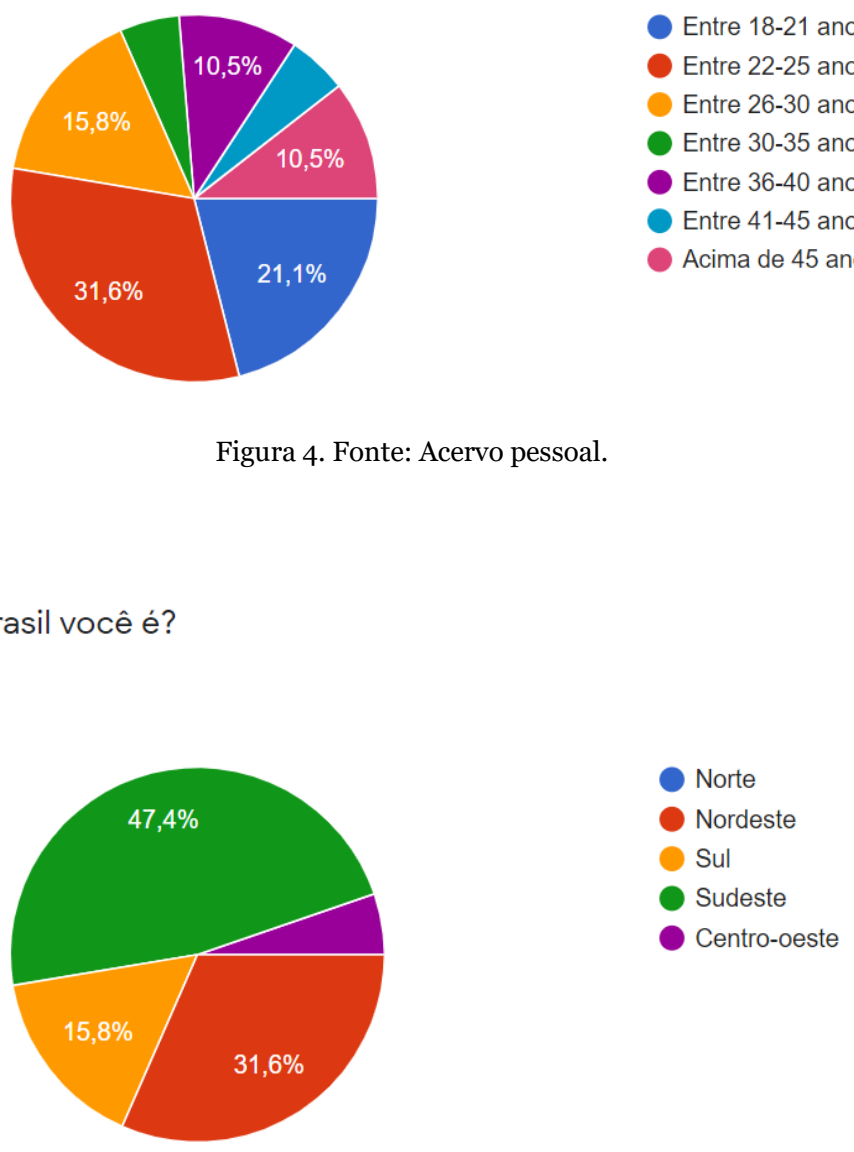

Figura 5. Fonte: Acervo pessoal.

Feito o perfil dos sujeitos, passamos a analisar suas respectivas respostas. Quando perguntados se acreditam que há uma hiperssexualização do corpo do homem por homens gays os sujeitos em unanimidade responderam que sim ( $\mathrm{Fi}$ gura 5), o que demonstra eles percebem as estruturas racistas que permeiam o imaginário social e contribuem para a formação da consciência coletiva de membros da comunidade LGBTQIA+.

Nesses termos, longe se buscar homogeneizar a comunidade LGBTQIA+, tão plural e diversa em sua composição, toma-se como recorte o imaginário de homens gays no intuito de problematizar uma possível consciência coletiva, que é estruturada no imaginário social desses indivíduos. Muito embora também não se busque uma universalização de homens gays, apura-se a percepção de homens negros a partir de experiências no meio dito LGBTQIA+. 


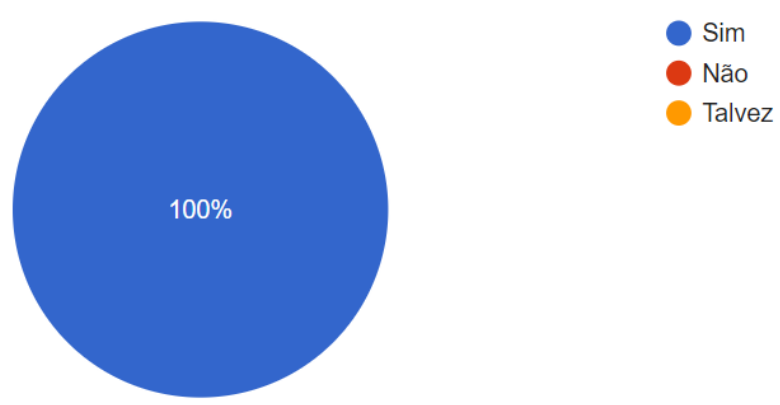

Figura 6. Fonte: Acervo pessoal.

A percepção a respeito desta hipersexualização de seus corpos, se dá através das falas, comportamentos e formas de se tratar. Nesse sentido, quando inquiridos sobre o motivo dessa percepção, as respostas variavam em termos, mas, convergiam no ideal de que os homens negros são sempre viris e possuem o pênis grande.

Sujeito 1: O homem negro é sempre um corpo disponível, viril, ativo e público. É o homem ideal para o sexo, mas apenas isso!

Sujeito 2: Quase ng(sic) quer assumir relacionamento no nosso meio ${ }^{4}$, com homens negros então...

$\mathrm{Ng}$ (sic) quer namorar o negro $22 \mathrm{~cm}$ do grindr5. No máximo um sexo mesmo.

Sujeito 3: Justamente pelo fato de relacionar o homem negro com o tamanho do pênis.

Sujeito 4: Sim, em vários grupos de internet (vulgo $L D R V^{6}$ ), os corpos negros são sexualizados, as pessoas olham a foto e já imaginam um pênis grande, $2 m$ de altura, voz grossa e corpo trincado. Pouco se importando no conteúdo humano da pessoa. ${ }^{7}$

Assim, percebe-se nas falas dos entrevistados que o imaginário social possui arquétipos do corpo do homem negro muito solidificados. Destarte, esse imaginário social vai configurar a consciência coletiva de membros da comunidade LGBTQIA+, no caso, homens gays, na qual encontramos as raízes desse pensamento na nossa história, que concebeu o "negão imagético" forte, viril e de pênis grande como o padrão hipersexualizado a ser reproduzido.

A consciência coletiva de homens gays formula e reproduz esse ideal colonialista e racista. Tendo em vista que acredita que o corpo negro está e estará a sua disposição apenas como um mero objeto sexual, sintetizando, o homem negro é reduzido de modo grotesco, ao seu pênis (SANTOS, 2013), sendo incapaz de ter aspecto de grandeza, também em outras instâncias de poder e prestígio social, empurrado a uma ética que não é a sua (FANON, 2008). Para subsidiar tal afirmativa, outros sujeitos deixam evidente em suas afirmativas:

Sujeito 5: Percebo que existe um estereótipo imaginário do homem negro dotado ativo buscado para sexo casual.

4 Aqui o sujeito se refere ao meio LGBTQIA+.

${ }_{5}^{5}$ Aplicativo de relacionamentos destinado a homens gays.

${ }^{6}$ Sigla do Grupo Lana Del Rey Vevo que possui grande mobilização no Facebook.

${ }_{7}^{7}$ As falas dos sujeitos foram colocadas em itálico e alinhadas à direita a fim de dar mais destaque e visibilidade ao que é dito. Algumas falas podem apresentar erros de grafia e gramática, pois foram utilizadas na íntegra. 
Sujeito 6: Sempre procura no homem negro grandes pênis, serem ativos, serem fortes e resistentes.

\begin{abstract}
Sujeito 7: Sim, pois nas relações homoafetivas, os homens negros só são procurados para a questão do prazer, onde muitas vezes em uma relação interracial o homem negro não é assumido, mostrando que a sociedade coloca o homem e a mulher negra como não dignos de se receber afeto.
\end{abstract}

Ainda a respeito de suas percepções, foi perguntado aos sujeitos se os mesmos já foram alvo de algum comentário no meio LGBTQIA+ que considerasse ofensivo ou racista do ponto de vista sexual. Assim, cerca de 68,4\% responderam que sim, $15,8 \%$ responderam que não e $15,8 \%$ não se recordavam (Figura 6).

\title{
Você já foi alvo de algum comentário no meio LGBTQIA+ que você considerou ofensivo ou
} racista do ponto de vista sexual?

19 respostas

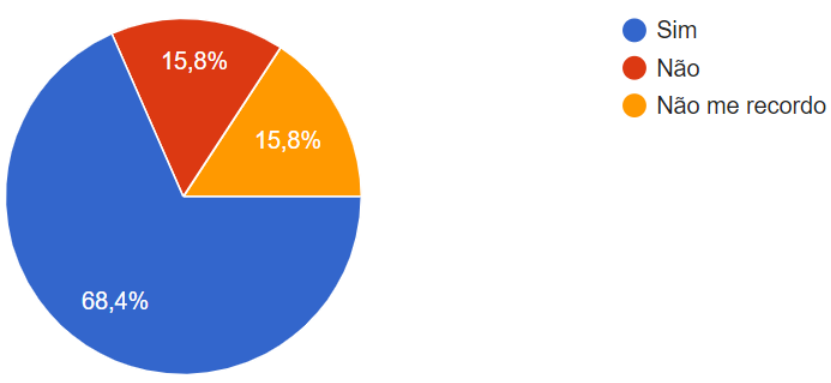

Figura 7. Fonte: Acervo pessoal.

Também foi questionado aos sujeitos sobre quais frases eles já ouviram a respeito do corpo do homem negro, os enunciados e discursos que habitam a consciência coletiva LGBTQIA+ aparecem nas falas dos entrevistados:

\footnotetext{
Sujeito 1: "tu deve ter o pauzao!" "Queria chupar esse picolé de chocolate" "tu é da cor do pecado". "Na cama deve ser um monstro".

Sujeito 2: Um cara já pediu pra eu gozar que nem um animal.

Sujeito 4: "Pelo tamanho da mão/pau imagina o pinto".

"Nunca vi um negão desse falar fino".

"Um negão desse tinha que ir malhar pra ficar com corpão".
}

As falas dos sujeitos, embora apresentem variações, nos direcionam a observar como a consciência coletiva de homens gays hipersexualiza e objetifica o corpo do homem negro. Atribui características unívocas a eles e, acima de tudo, dispensam quaisquer outras negando-os direito a subjetividade.

Nesse contexto, conforme Fanon (2008), o negro é jogado numa ética que não é sua e, neste caso, dentro da consciência coletiva de membros da comunidade LGBTQIA+, num ideal hipersexualizado. O que nos leva a pensar sobre essa consciência coletiva, com vistas a desconstruí-la, dando ênfase à voz dos oprimidos, através dos estudos decoloniais, além de estranhar, questionar e duvidar da forma como ela foi estruturada e produzida no contexto colonial com um queer decolonial, que mostra a inconformidade desses corpos e desses sujeitos, rompendo e desvelando, portanto, esse imaginário e essa consciência coletiva. 


\section{Considerações Finais}

Buscou-se no presente trabalho trazer a percepção de homens negros sobre a construção do imaginário de gays sobre seus corpos. Nesse sentido, a partir dessas narrativas, analisou-se percepções sobre o corpo do homem negro com base no pensamento durkheimiano, dos estudos decoloniais e o queer decolonial.

As correntes teóricas que cuidam das questões humanas são fundantes para percebermos estruturas de dominação e opressão que operam nas teias sociais. Com isso, percebe-se que a consciência coletiva de membros da comunidade LGBTQIA+ ainda reproduz racismo e estigma num país onde mais de $50 \%$ da população é negra. Além do mais, essa mesma consciência traz para dentro da comunidade LGBTQIA+ impasses que passam pelo recorte de raça.

Embora não tenha sido dito pelos sujeitos participantes da pesquisa, apreende-se de suas falas que essa hiperssexualização se dá por homens gays brancos. Que desprezam as diversas faces da subjetividade do homem negro, e os trata como objetos sexuais aptos a saciar seus desejos.

Finalizar as discussões em torno da temática no presente trabalho é uma tarefa impossível, dada nossa formação cultural, étnica e, acima de tudo, colonial. Tendo em vista que as nuances sociais contribuem, também, para a formação de consciências coletivas e desconstruí-las leva tempo e debates. O presente trabalho deixa mais perguntas do que respostas: há espaço para afetividade para além do sexo em relação ao homem negro entre homens gays? A comunidade LGBTQIA+ está disposta a pensar sobre o privilégio branco?

Acreditar que é possível decolonizar é corpo negro é fundamental. Os passos iniciais se dão com o processo de (re)pensar estruturas sociais e discursivas para, assim, transcendermos a lógica colonialista e racista que configura imaginários sociais e as consciências coletivas.

É notório que há uma inquietação, como os estudos decolonais e a teoria queer, que estão interessados em dar voz aos corpos visibilizados, aos gritos silenciados de populações dissidentes. O presente ensaio deu voz a uma parcela desses homens negros que não suportam mais o local de subordinação e subalternidade que a sociedade os colocou e espera que eles desempenhem os papeis por ela designados.

Recebido em o8 de janeiro de 2021. Aprovado em 12 de abril de 2021. 


\section{Referências}

ALMEIDA, Suely Creusa Cordeiro. Quarto Grande e Senzala. Revista História da Biblioteca Nacional, 17 (93): 23-25, 2013.

DURKHEIM, Emile. Da Divisão Social do Trabalho. São Paulo: Martins Fontes, 1995.

FANON, Frantz. Os condenados da terra. Rio de Janeiro: Civilização Brasileira, 1968.

FANON, Frantz. Pele negra, máscaras brancas. Salvador: UDUFBA, 2008.

FOUCAULT, Michel. Vigiar e Punir: nascimento da prisão. Tradução de Raquel Ramalhete. Petrópolis, RJ: Vozes, 2014.

GOHN, Maria da Glória. Empoderamento e participação da comunidade em políticas sociais. Revista Saúde e Sociedade, 13 (2): 20-31, 2004.

MISKOLCI, Richard. Teoria Queer: um aprendizado pelas diferenças. Belo Horizonte: Autêntica Editora, 2020.

PEREIRA, Pedro Paulo Gomes. Queer Decolonial: quando as teorias viajam. Revista Contemporânea, 5 (2): 411-437, 2015.

PEREIRA, Adriana Soares; SHITSUKA, Dorlivete Moreira; PARREIRA, Fábio José; SHITSUKA, Ricardo. Metodologia da Pesquisa Científica. Rio Grande do Sul: UFSM, 2018.

QUIJANO, Aníbal. "Colonialidade do poder, eurocentrismo e América Latina". In: LANDER, Edgardo (org.). A colonialidade do saber: eurocentrismo e ciências sociais - perspectivas latino-americanas. Buenos Aires: CLACSO, 2000. pp. 107-130.

RODRIGUES, Walter Hugo de Souza. Desmistificando a sensualidade naturalizada do ébano: Um estudo acerca da objetificação do corpo do homem negro. Revista Cadernos de Gênero e Tecnologia, 13 (41): 267-284, 2020.

SANTOS DA COSTA, Oli. Exu, o orixá fálico da mitologia nagô-yorubá: demonização e sua ressignificação na Umbanda. Tese de Doutorado, Ciências da Religião, Pontifícia Universidade Católica de Goiás, 2012.

SOUZA, Rolf Malungo Ribeiro de. As representações do homem negro e suas consequências. Revista Fórum Identidades, 6 (6): 98-115, 2009.

UZEL, Marcos. "O estigma do super negão: sexualidade em debate numa peça do bando de teatro Olodum". In: OLIVEIRA, Felipe Henrique Monteiro (org.). Nudez em cena: insurgências dos corpos. São Paulo: Pimenta Cultural, 2019. pp. 88-103. 


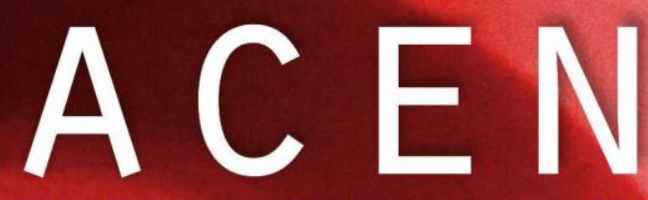

REVISTA DE ANTROPOLOGIA DO CENTR

$\sum$

a

(5)

4

$\vdash$

$\infty$

Z

인

z

Revista quadrimestral editada pelo Programa de Pós-Graduação em Antropologia Social da UFMT, desde 2014. ISSN : $2358-5587$ 